\title{
QUANG TRI OLD CITADEL IN VIETNAM ON THE PATH TO SUSTAINABLE TOURISM: HISTORICAL MEMORY AS AN INSTRUMENT FOR A REQUALIFICATION PROJECT
}

\author{
F. Pugnaloni a, C. Carlorosi b, Le Ngoc V. A. c \\ a Professor, DICEA, Università Politecnica delle Marche, Brecce Bianche st. 60131 Ancona IT - \\ f.pugnaloni@univpm.it \\ b PhD Student, DICEA, Università Politecnica delle Marche, Doctoral School on Engineering Sciences - \\ c.carlorosi@univpm.it \\ c PhD Student, DICEA, Università Politecnica delle Marche, Doctoral School on Engineering Sciences - \\ v.a.lengoc@univpm.it
}

KEY WORDS: Sustainable Tourism, Historical Perspective, Old Citadel System, Walls Recovery, Architectural Design

\begin{abstract}
:
The aim of this study is searching and forming about the innovative solutions in preservation of the culture heritage and historical sites. The restoration of damaged heritage represents a fundamental theme in the architectural debate to provide answers at an international level. The history of civilisation reveals that the great cities of the past were destroyed by war. These destructive forces threaten the structural heritage of our great cities, putting the entire political and religious system in jeopardy.

The research concentrates on the case study of Quang Tri Citadel where the culture and history experienced two wars, the French and the American one.

The methodology of this study is based on the field survey, oral history, and social participation. Therefore it is appropriate to include a historical perspective in the project, assuming it unfolds on three levels within the defensive belt represents a constant and integral element of the scheme: the technical recovery of the walls, the functional transformation of the existing foundation in order to improve sociological topics, the level of architectural studies and proposals. The result of this research illustrates a new approach of the scientific debate to the cultural and historical values of the sites.
\end{abstract}

\section{INTRODUCTION}

The restoration of damaged heritage represents a fundamental theme in the architectural debate to provide answers at an international level. The Architectural Section of the Department of Civil and Building Engineering and Architecture of the Università Politecnica delle Marche is taking part in the debate with activities and research linking the conservation of memory and places of historical significance to research into solutions compatible with the sustainability of these locations (Figure 1). The history of civilisation reveals that the great cities of the past were destroyed by war. These destructive forces threaten the structural heritage of our great cities, putting the entire political and religious system in jeopardy. This is the case of the Ancient citadel of Quang Tri, situated in the Province of Quang Tri in central Vietnam and founded in 1809, forever recorded in history and erased architecturally by the battle in 1972 .

The Citadel system in Vietnam is an expression of the history, culture, technical and artistic heritage of the society of a specific historical period; Vietnamese society generated a very interesting urban type, documenting factors such as the orientation, topography, a primarily agrarian economy revealing similarities between the most ancient Asian traditions and elements of fortified European cities. Generally, these are attributed to the Vauban style in the case of Vietnamese cities dating back to the Nineteenth century. Chinese colonial occupation lasted over a thousand years in Vietnam. French colonialism started in the second half of the nineteenth century and lasted less than a century, leaving an important heritage of intellectual and urban development, influencing the infrastructure of major cities in Vietnam. These places serve the function of historical reappropriation just like the oxymoron between regulation and fruition provides resolutive elements in the definition of innovative strategies aimed at motivating cultural and jointly liable tourism, the impact of which consists of potentially positive impacts on socio-economic growth of the populations involved.

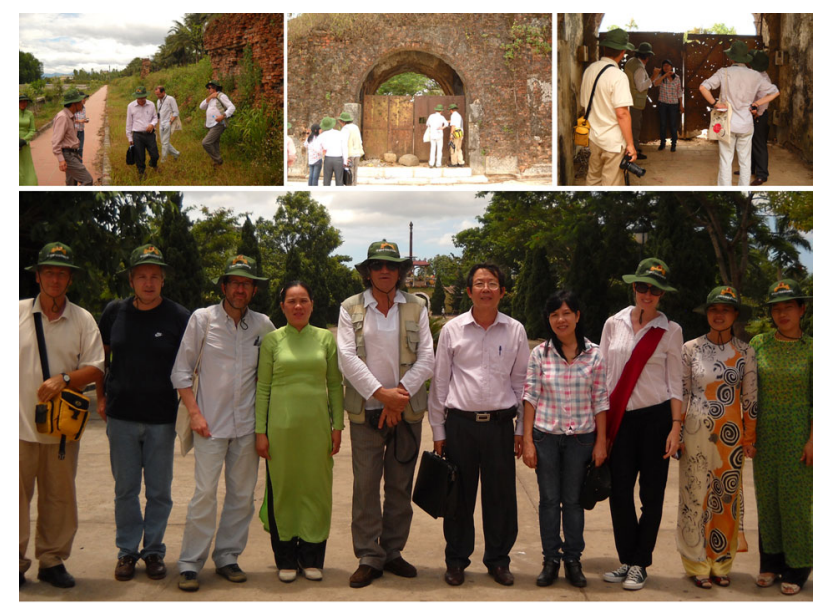

Figure 1: The Italian and Vietnamese scientific staff and the local authorities visting Quang Tri in June,2011 


\subsection{Urban, infrastructural and climate overviews about case study}

Quang Tri citadel is located in the center town of Quang Tri which belong to Quang Tri province in Vietnam.

Quang Tri town is a small zone with $40 \mathrm{~km} 2$ and 22.760 people of population. In general, Quang Tri town is the area with underdeveloped economics, most of people work in agriculture and fishing. In addition, Quang Tri is faced with low infrastructure. The street is narrow without drainage systems, especially all the streets around citadel. Besides that, the citadel is located beside Thach Han River with $230 \mathrm{~m}$ distance. This is the lowest place of Quang Tri town.

Therefore, in the rainy season, the citadel and all streets flood with water. In fact, in 1983 and 1990, the highest water level was from $2 \mathrm{~m}$ to $2.5 \mathrm{~m}$. These were the causes of the rapid degradation and road damage, and erosion impacted on the citadel. However, Quang Tri citadel is located in a good situation with the convenience of waterway, road, and railway. There are the connections inside the province by road and waterway, the connection of Quang Tri town with Cua Viet port, and other ones by the railway from North to South. On the basis of these advantages and disadvantages, the preservation and sustainable development are urgent problems.

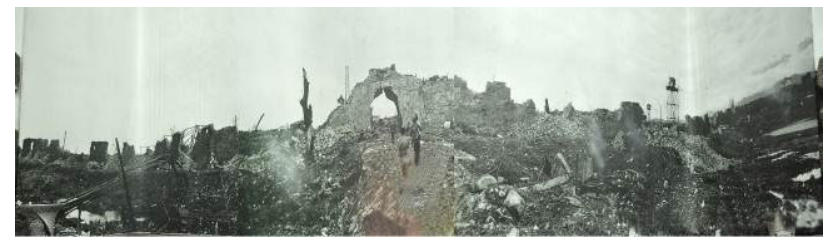

Figure 2: 1972, Quang Tri Old Citadel after the battle

\subsection{The formation and the history Quang Tri Citadel}

Quang Tri citadel is a historical monuments of Vietnam which is famous for the second battle of Quang Tri began on June $28^{\text {th }}$ and lasted 81 days until September $16^{\text {th }} 1972$, between Vietnam People's Army and Army of the Republic of Vietnam backed by United States of American.

The formation of Quang Tri citadel goes through many historical periods.

Firstly, Gia Long, the first king of Nguyen dynasty, built the citadel in 1809 .

It was built with clay soil but it was destroyed gradually because of climate. In 1827, Minh Mang king carried on rebuilding by brick, made of the mixture of calcium hydroxide, and condensed sugarcane.

The citadel's shape is a square. The perimeter of the wall is approximately $2000 \mathrm{~m}$, the area is 3 kilometer square. The wall is $6-7 \mathrm{~m}$ in thickness of the feet and $2.5 \mathrm{~m}$ of the top. The citadel has four main doors at North, East, South, and West with the dome form with $3.4 \mathrm{~m}$ of wide, the top is observatory with a curved roof.

The citadel is surrounded by a water canal system and the four corners are the four high forts. Following the history documents, inside of the citadel there are about nine buildings, Hanh Cung (is the biggest building of king office and festival organization), Tuan $\mathrm{Vu}$, An Sat, Lanh Binh, Ty Phien, test school, military camps, flagpole. In the years from 1809 to 1945 , the Nguyen dynasty took this place as the military stronghold and administrative headquarters.

From 1929 to 1972, the French built more houses, such as prison, and turned this place into a place of detention of people with opposing political views and more police courts, soldiers camps, tax authorities officers.
After the Quang Tri battle 1972, the citadel was destroyed, many parts of mortal disappeared, only the brick part remained. Some brick part were broken, as can be seen in the soil inside (Figure 2).

In addition, part of the old prison was built from brick, concrete and rock; nowadays only the rock part still remains. It was also destroyed by bombs and bullet.

Each piece of land has blood and bones of those soldiers (Figure 3 ), therefore, the citadel can be considered as a common grave which buried about 10 thousand people, mostly in their twenties.

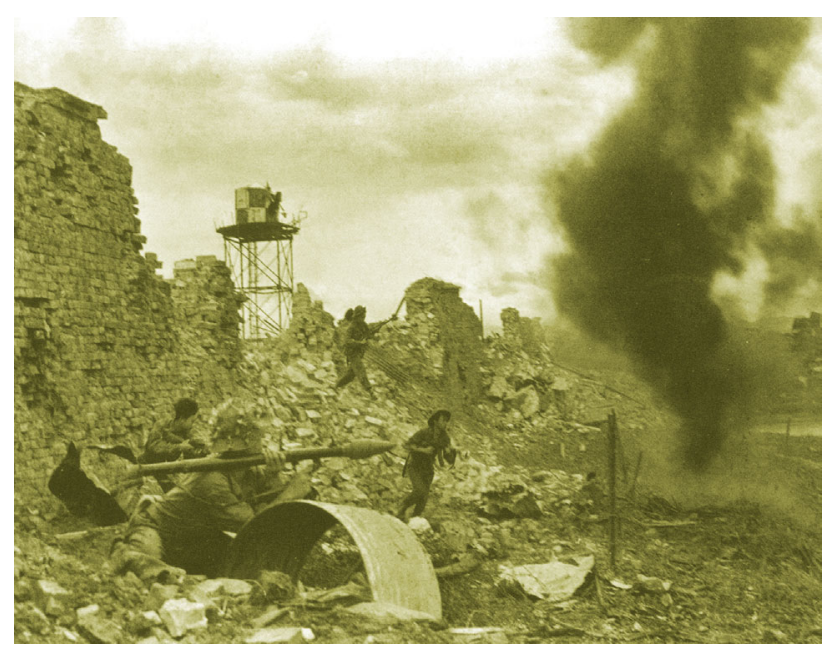

Figure 3: Picture from Quang Tri battle, 1972

\section{THE RE-BIRTH OF QUANG TRI OLD CITADEL}

The walls are the cardinal element underlying a variety of themes representing the meaning expressed by Quang Tri Old Citadel.

The walls surround an extensive area where the layout of two orthogonal axes oriented on the basis of the cardinal points. The point where they meet is currently marked by an altar devoted to the cult of ancestors. Four gates correspond to the extremities of the two axes. The urban shape is square "in line with ancient Chinese theories which imagined the earth to be quadrangular" (M. Morini, " Atlante dell'urbanistica").

The orthogonal scheme does not evolve rigidly except in its essential lines and it is characterised by large open spaces.

The defensive walls record the overlay of historical memory throughout different periods (Figure 4). These were ruined by wars. Shattered bricks provide clear evidence of the violation of the sanctity of the walls and the human events that unfolded in this place.

The devastated walls were covered by thick vegetation like a citadel taken by force (Figure 5).

It is appropriate to include a historical perspective in the project, assuming it unfolds on three levels within which the defensive belt represents a constant and integral element of the scheme: the technical recovery of the walls, the functional transformation of the existing foundation in order to improve sociological topics, the level of architectural studies and proposals. 


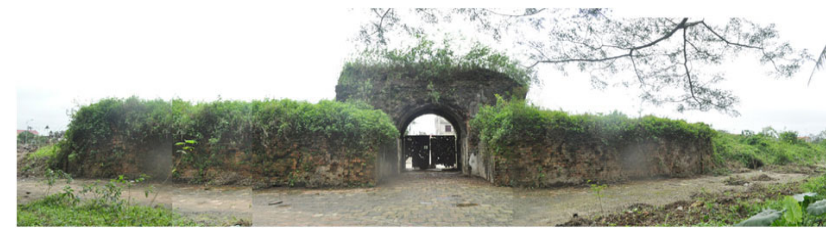

Figure 4: East gate front of Quang Tri citadel

2.1 The level of technique and social participation: the recovery of the walls

The planned restoration of the historical walls requires existing parts to be restored in compliance with best workmanship standards and cutting edge building techniques in accordance with the original construction.

The restoration plan will respect the original structure and limit the extent of substitution and removal, instead of completing the parts that crumbled and were destroyed.

The required operations will take place in the following phases: - historical and documentary analysis, on the basis of which potential construction scenarios will be proposed to determine the heterogeneity of materials and techniques used;

- direct analysis of the structure;

- enquiries and proof, to determine the mechanical and chemical-physical characteristics of the materials of the walls;

- identification of contemporary materials compatible with existing materials to restore the structure, safeguarding its aesthetic and historical identity.

A training course and a laboratory will be established for the above operations, with the presence of young Vietnamese technicians which will be guided by expert teachers.

In addition to the specific skills of technicians, the process for the recovery of the walls could be realized through the work of volunteers; these volunteers must be chosen between the inhabitants of the Province of Quang Tri, but they also could be intellectuals which are interested in the conservation of this heritage.
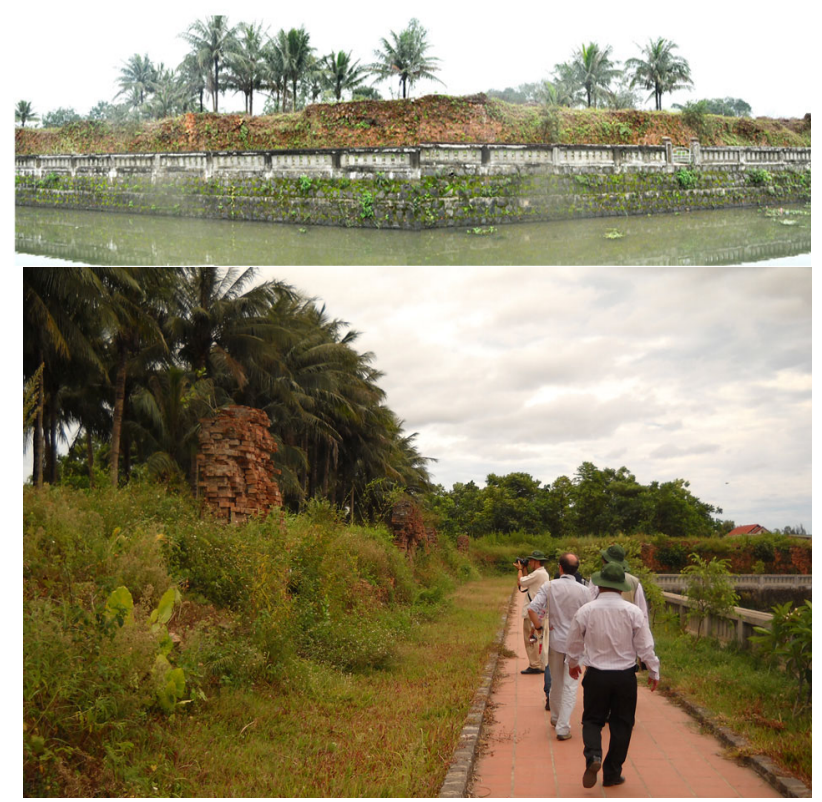

Figure 5: Quang Tri, actual views of the wall
2.2 The level of sociology and communication: museumification on the path to sustainable tourism

A historical site in general and Quang Tri citadel in particular includes many values such as cultural, historical, and architectural values (Figure 6).

Cultural value is the patriotism; it affects the visitor with the significance of patriotism education of its country. The historical values mark a flourishing period of the Nguyen Dynasty, the evidence of cruel war and the heroic struggle of Vietnamese.

Therefore keeping this value is the preservation and proposal solutions for the future.

The building site at Quang Tri has substantial untapped potential; this model should be included in the more traditional tourist itineraries as a strategic point in planning innovative tourism along the major itineraries of the South Central coast of Vietnam to enhance local attractions.

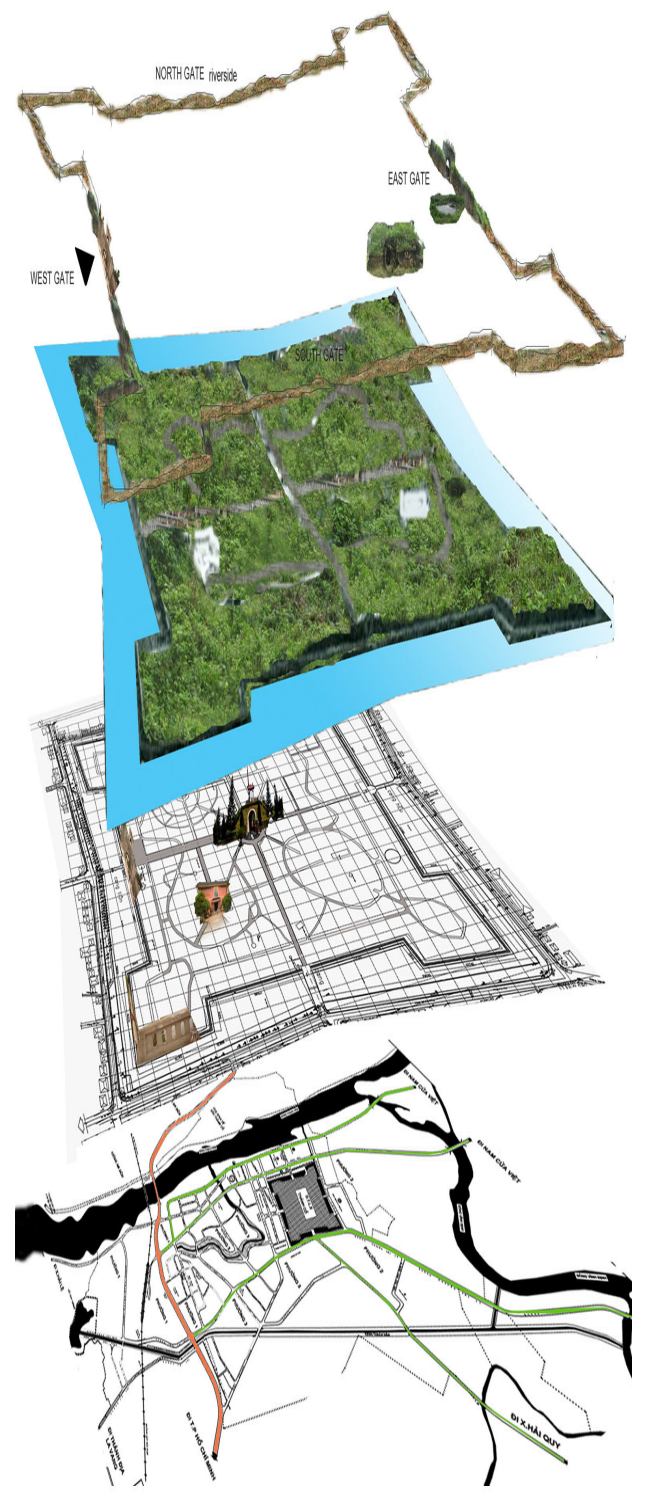

Figure 6: The categories of Quang Tri Complex: connections, existing buildings, green spaces and the walls 
These attractions represent instruments for the international promotion of the territory of Central Vietnam, where there are current initiatives such as "National Tourism Year 2012" promoted by Thua Thien Hue Province, involving the important city of Hue, which was the last imperial capital of Nguyen dynasty (1802-1945) and is one of the UNESCO world Heritage sites, and where the model of the fortified citadel is put forward in the Ancient Citadel of Hue. The activities of this year are an occasion to advertise the potential of tourist attractions in Central Vietnam.

It will be the result of a participatory process involving population, historians, and social scientist based on the historical awareness acquired. It will also represent a new idea of jointly liable social tourism.

Furthermore the museum is not only the place to put items on display, but also a digital world to promote both the history of Quang Tri and the monumental sites in the Asian countries.

In addition, such a digital museum will use Information Technologies for communication between past and present.

In fact, advanced technologies will be applied through the use of digital applications that will play a fundamental role as means of communication: virtual images will represent to the visitors the architectural analysis of the system of Old Vietnamese Citadels, the memories of the war in Quang Tri, the researches related to the identity of the Asian territories and 3D documentation of archaeological sites.

Therefore the museum will promote Virtual Exhibitions of multimedia data, digital documentation and real-time applications about architectural and historical culture.

The aim of the use of innovative technologies is to involve the visitor to improve the dialogue between the historical knowledge and its contemporary comprehension.

\subsection{The level of architectural design: formal and compositional research}

The third level concerns the architectural analysis and the conception of the project.

As mentioned before, the other value of the historical site is architecture, because it marks the morphological features of a period; specifically, the citadel has a role in recognizing the form of military wall in the Vietnam War.

Therefore at a compositional level, the walls should not be disturbed by a plethora of architectural objects and the area within the walls should be almost completely free.

The proposal of design concept is very important in this type of construction. In fact, a moderate work must be in harmony with the surroundings, but also leave the impression to the visitors providing emotions to the viewers with the sustainable connection.

Therefore, the project process works through accurate 3D architectural representations of the Citadel of Quang Tri, in order to study the impact of the project on its environment. The three-dimensional visualization is used as a valid instrument both to design the museum system and to represent the proper hypothesis of architectural interventions.

The museum, which will use applied technologies, could be a building located underground as a part of overall. It will be an integral part of the surrounding landscape, as the factors that currently exist and the sustainable development of the project depends on this impaction.

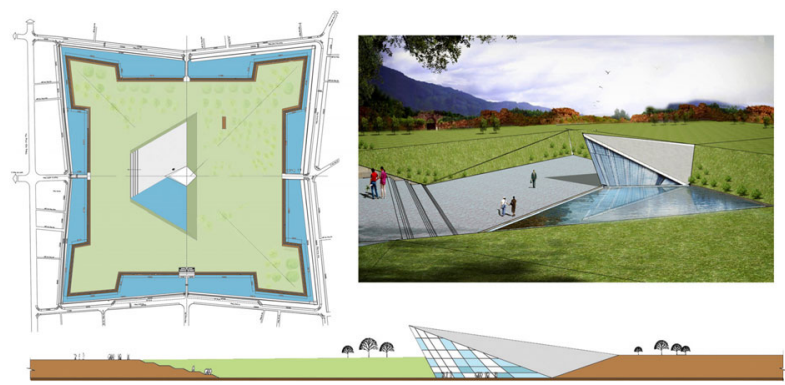

Figure 7: Analysis of the impact of the project on its context

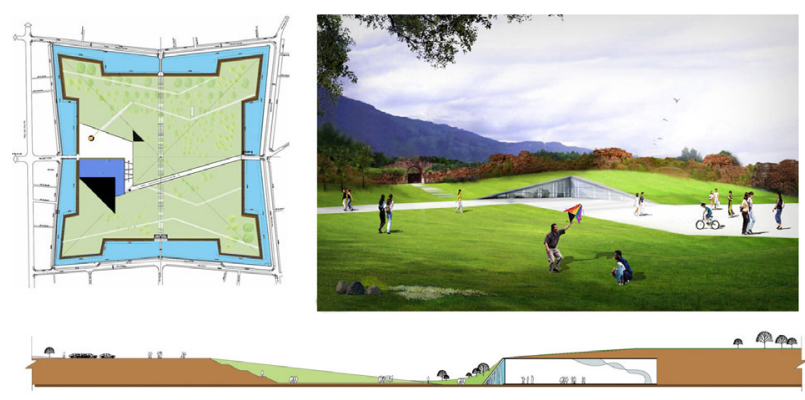

Figure 8: Studies for the compositional research for an underground museum

Some hypothesis about the design idea of the museum's apparatus are studied through $3 \mathrm{D}$ perspectives to achieve the highest concord with its context.

The museum could be immersed in a green space simulating the memorial space. It is created from the same layer with the surrounding objects with the entrance on lower level from the plan ground (Figure 7).

The second idea (Figure 8) highlights the idea of harmony.

The museum is placed underground dividing the grass in two layers having different altitude: the highest is at the same level of the plan ground and the lowest has the entrance giving the feeling of unity between the two objects.

Finally the free area inside the wall represent a solution which is guided from the memory of the past.

\section{CONCLUSIONS}

Old Citadels built by South-East Asian civilisations have a specific historical relevance and their own features.

They provide a basis for scientific thought on themes that safeguard sustainability and the relationship with neighbouring regions.

The path to sustainable tourism combines cultural and environmental factors and is functional to the development of social-cultural tourism, in search of real evidence of different reference contexts - to produce benefits on socio-cultural areas of interest. 


\section{References from Proceedings and Books:}

AA VV, 2005. Lich su quan doi nhan dan Viet Nam. Published by Quan Doi Nhan Dan.

AA VV, 2012. Ky uc 81 ngay dem thanh co Quang Tri va nhin lai tran chien mua he do lua Duong 9 Nam Lao. Published by Van Hoa Thong Tin.

Futagawa, Y., 2009. GA contemporary Architecture: Museum v.2. Published by ADA Editors.

Griffith, F., Dennis, P., 2006. The Vauban Fortifications of France. Published by Osprey.

Morini, M., 1963. Atlante dell'urbanistica. Editore Ulrico Hoepli, Milano.

Pugnaloni, F., 2006. Technologic and cultural development for the defence of the architectural heritage in Vietnam: the case of the complex of Huè monuments. 11th International Seminar forum UNESCO /University and Heritage. UniversityPress, Firenze.

Pugnaloni, F., Issini, G., Dang, M.N., 2007. Cultural Heritage knowledge and research in the Italy-Vietnam Cooperation. Edizioni Ripesi, Ancona.

\section{References from websites:}

www.thixaquangtri.gov.vn

www.dulich.thuathienhue.gov.vn 
